\title{
Neonatal hyperthyroidism alters the development of behavioral arousal and inhibition in the mouse
}

\author{
JAMES M. MURPHY and Z. MICHAEL NAGY \\ Bowling Green State University, Bowling Green, Ohio 43403
}

\begin{abstract}
Thyroxine injections of neonatal mice at 1,2, and 3 days of age yielded higher activity levels during the second and third postnatal weeks compared to saline controls, but did not result in an earlier ontogenetic activity peak, which would have been indicative of accelerated development of inhibitory functioning. However, in the second experiment, hyperthyroid mice demonstrated a significant increase in activity following scopolamine injection as early as $\mathbf{1 5}$ days of age, whereas controls showed a similar increase at 17 days of age. This finding suggests that neonatal hyperthyroidism results in earlier development of the cholinergic system.
\end{abstract}

Both rats (Campbell, Lytle, \& Fibiger, 1969) and mice (Nagy, Murphy, \& Ray, 1975) exhibit an inverted U-shaped ontogenetic locomotor activity curve, with the decline in activity levels following the peak presumably reflecting the emergence of inhibitory functioning. The forebrain cholinergic system is one of the biochemical systems thought to mediate this inhibitory capacity by modulating brainstem excitatory centers (cf. Campbell et al., 1969; Carlton, 1963).

Experimental hyperthyroidism in the neonatal rat and mouse accelerates maturation of numerous physiological and behavioral capacities (Davenport \& Gonzalez, 1973; Murphy \& Nagy, in press; Schapiro, 1968), and among the aspects of central nervous system development shown to be affected by early thyroid hormone levels are indices of cholinergic functioning (Geel \& Timaras, 1967; Hamburgh \& Flexner, 1957; Schapiro, 1968). Thus, neonatal hyperthyroidism would be expected to yield accelerated development of inhibitory capacities, one indication of which would be an earlier peak in the ontogenetic activity curve. A previous investigation of thyroid hormone effects upon the development of behavioral activity was conducted with neonatal triiodothyronine injections to rats, and an earlier peak in the ontogenetic curve was not obtained (Davenport, Hagquist, \& Hennies, 1975).

The purpose of the present study was to assess the effect of early thyroxine injections upon the development of behavioral arousal and inhibition in the mouse. Since thyroxine is a slower acting thyroid hormone than triiodothyronine (Peterson, Nataf, Chaikoff, \& Ragupathy, 1966) and since the mouse develops somewhat faster than the rat (Agrawal \& Himwich, 1970; Nagy et al., 1975), the time course of the hormone effect may differ from that previously observed.

This research was supported by a grant from the National Institute of Child Health and Human Development (HD-09145-01) to the second author. Requests for reprints should be sent to Z. Michael Nagy, Department of Psychology, Bowling Green State University, Bowling Green, Ohio 43403.

\section{EXPERIMENT I}

\section{Method}

Subjects. The subjects were 20 Swiss-Webster mice (Mus musculus) born and reared in 30.4 by 18 by $12.8 \mathrm{~cm}$ polyethylene cages with wire grid tops and wood chips on the floor. Mothers remained with the pups at all times, except during testing sessions and other experimental procedures. Nesting material was provided and ad-lib food and water were available. The colony room was on a normal 12-h light-dark cycle beginning at $0800 \mathrm{~h}$ and was maintained at $24 \pm 1^{\circ} \mathrm{C}$.

Apparatus. Testing was carried out in clear Plexiglas cages measuring 19.4 by 6.4 by $9 \mathrm{~cm}$. Red-filtered light sources and photocells, placed $3.4 \mathrm{~cm}$ from each end, enabled the recording of activity on apparatus located outside the soundproofed chamber. One activity count was registered each time the subject crossed alternate photocell beams. Grid floors were constructed of 1 -mm-diam stainless steel rods, spaced $4 \mathrm{~mm}$ center to center, which extended parallel to the length of the cage. The cages were enclosed in a humidity-controlled environmental chamber maintained at $24 \pm 1^{\circ} \mathrm{C}$. Two 60 -W fluorescent ceiling lights provided illumination for the chamber, and a ventilation fan furnished a 74-dB ambient noise level.

Procedure. Five litters were selected which had been born on the previous day and contained at least 10 pups. Four males and four females with equal or near-equal weights were selected from each litter and toe-clipped for identification. Extra pups were culled, leaving all litters with eight subjects. Two males and two females from each litter were randomly assigned as hormone-treated subjects and received $1 \mu \mathrm{g} / \mathrm{g}$ body weight $\mathrm{i} . \mathrm{p}$. injections of thyroxine (L-thyroxine, Sigma Chemical Company) in saline suspension at 1,2 , and 3 days of age. The remaining four pups in each litter were assigned as controls and were similarly injected with saline.

Four mice were subsequently selected from each litter, one male and one female from each of the saline- and thyroxinetreated subjects, and were tested for $2 \mathrm{~h}$ daily from 9-20 days of age. Activity testing sessions were conducted at the same time each day between 0800 and $1700 \mathrm{~h}$, the normal light period of the day-night cycle.

\section{Results and Discussion}

Figure 1 depicts the mean number of crossings as a function of hormone treatment and age. Hormone, Sex, and Age were the factors considered in a three-way repeated measures analysis of variance. Activity changed significantly with Age $[F(11,176)=36.18, p<.0005]$, 


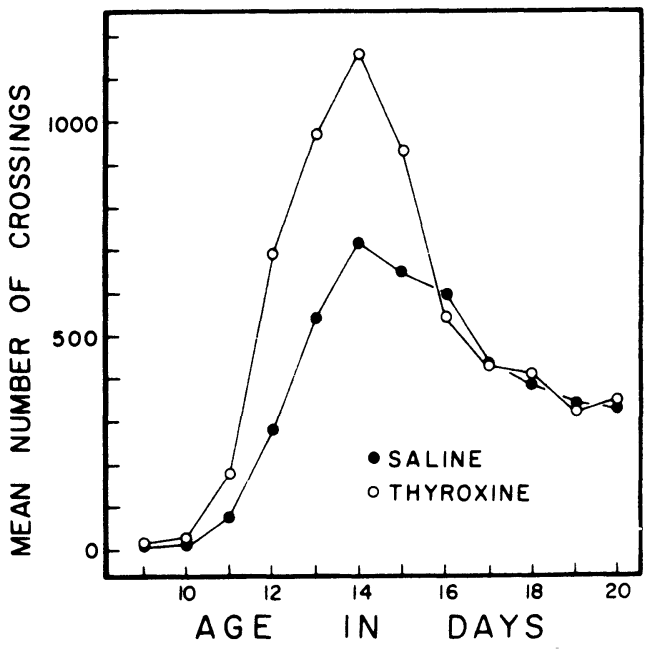

Figure 1. Mean activity scores as a function of hormone treatment and age.

rising to a peak at 14 days and declining with further maturation. This ontogenetic activity pattern is consistent with previous studies on altricial rodents and parallels the sequential development of brainstem excitatory and forebrain inhibitory mechanisms (Campbell et al., 1969; Nagy et al., 1975; Oakley \& Plotkin, 1975). Figure 1 illustrates that the Hormone by Age interaction $[\mathrm{F}(11,176)=3.85, \mathrm{p}<.0005]$ was a consequence of the more räpid increase and higher peak in activity for the thyroxine-treated mice compared to saline controls, a finding which suggests either potentiated and accelerated development of arousal mechanisms or accelerated locomotor capacities. Recent evidence with adult subjects indicates that experimental hyperthyroidism increased behavioral activity by potentiating the adrenergic arousal system (Emlen, Segal, \& Mandell, 1972; Engstrom, Strombom, Svensson, \& Waldeck, 1975; Engstrom, Svensson, \& Waldeck, 1974).

Evident in Figure 1 is the fact that neonatal hyperthyroidism did not produce an earlier ontogenetic activity peak, in agreement with Davenport et al. (1975). However, clear interpretation of this finding as indicating that early hyperthyroidism did not alter the development of inhibitory capacities is complicated by the concurrent potentiation of arousal. If the ontogenetic activity peak reflects a shift in arousal-inhibitory balance, then the enhanced arousal exhibited by the hyperthyroid mice would require a relatively more mature level of inhibitory control to affect that shift.

\section{EXPERIMENT II}

Since Experiment I did not provide unequivocal behavioral evidence concerning the effect of neonatal hyperthyroidism on development of cholinergic inhibitory capacities, further assessment of that possibility was accomplished by determining the age-related response to the anticholinergic drug scopolamine for thyroxine- and saline-treated mice. A previous investigation found that scopolamine increased activity in 19. but not 15-day-old Swiss-Webster mice (Ray, 1975).

\section{Method}

Subjects. Postnatal thyroxine injections were administered to 120 mice, while an equal number of controls received saline. The injection procedure, dosages, housing conditions, and apparatus were as described in Experiment $I$.

Procedure. At 15, 17, and 19 days of age, separate groups of 20 males and 20 females from each of the thyroxine and saline subject groups were tested for a $1 / 2$-h adaptation period in the activity cages. This initial period enabled equating activity levels for assignment to subsequent groups. One-half of the subjects in each group were then given i. p. injections of scopolamine $(1 \mathrm{mg} / \mathrm{kg}$ scopolamine hydrochloride, Sigma Chemical Company) in saline solution, while the remaining animals received vehicle injections. The dosage employed was based upon Ray's (1975) dose-response study, which indicated that $1 \mathrm{mg} / \mathrm{kg}$ produced maximal activity increments in 19-day-old subjects. Immediately following injections, activity was recorded for an additional $2 \mathrm{~h}$.

Thus, the experimental design entailed four groups of 10 males and 10 females at each age tested. Two groups received saline as neonates and either saline or scopolamine in the postinjection testing period ( $S-S$ or $S-D$, respectively), while two analogous groups received thyroxine as neonates (T-S or T-D).

\section{Results and Discussion}

The mean pre- and post-injection activity scores are depicted in Figure 2 as a function of Age, Group, and 15-min Interval. A repeated measures analysis of variance was performed upon the data for the preinjection period, the factors being Age, Hormone, Drug, Sex, and 15-min Interval. Results of the analysis indicated general increase in activity with Age $[F(2,216)=$ $7.23, \mathrm{p}<.005]$ as well as a significant Interval effect

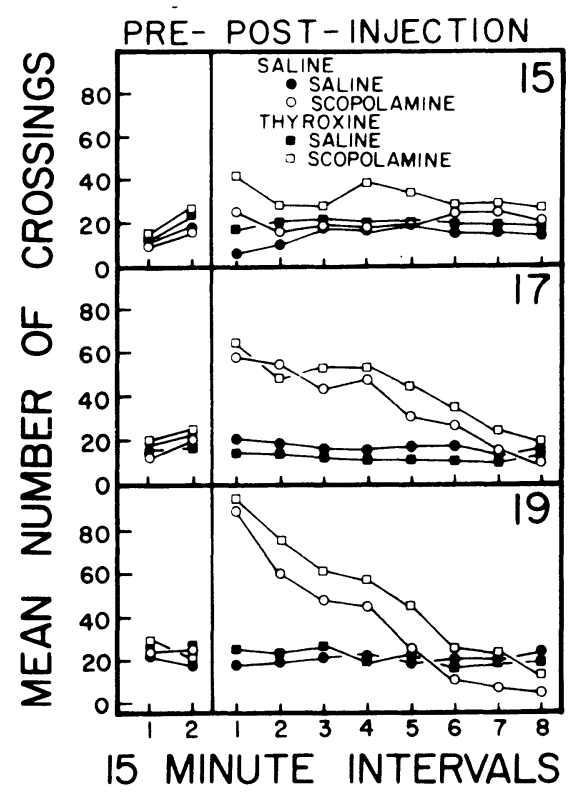

Figure 2. Mean pre- and post-injection activity scores as a function of age $(15,17$, or 19 days of age), group (S-S, S-D, T-S, or T-D), and 15-min intervals. 
$[F(1,216)=12.48, p<.001]$. An Age by Interval interaction $[\mathrm{F}(2,216)=12.42, \mathrm{p}<.0005]$ reflected an increase in activity from the first to second 15 -min interval at 15 and 17 days of age but a decrease at 19 days. The thyroxine-treated mice proved to be only slightly more active than saline controls during the pre-injection period $[F(1,216)=3.74, p<.06]$. No significant differences occurred which would question adequate matching of the thyroxine and saline experimental groups (T-D and S-D) with their respective controls (T-S and S-S).

Separate analyses conducted at each age for the post-injection activity scores indicated that 17 - and 19-day-old T-D and S-D groups were more active than T-S and S-S controls regardless of neonatal hormone treatment $[F s(1,72) \geqslant 12.96$, ps $<.001]$. The significant main effect for Interval and the Drug by Interval interaction at 17 and 19 days (all ps $<.0005$ ) were due to the initially high activity levels of the scopolamineinjected groups followed by consistent decreases in activity over the 2-h session.

At 15 days of age, individual comparisons showed that a main effect for Drug $[F(1,72)=4.79, p<.05]$ was a result of the T-D group being more active than the control T-S group $[\mathrm{F}(1,72)=4.24, \mathrm{p}<.05]$, whereas the S-D and S-S groups did not differ $[F(1,72)=1.08]$. A significant Drug by Sex by Interval interaction $[F(7,504)=3.64, p<.005]$ resulted from the females being generally more active during the initial part of the session in response to scopolamine.

The findings for groups treated with saline in the neonatal period are in agreement with results obtained for normally reared mice (Ray, 1975). Fifteen-day-old mice showed no apparent increase in spontaneous locomotor activity when injected with scopolamine, while the substantial response to scopolamine at 17 days of age suggests that forebrain cholinergic inhibitory control over behavioral arousal emerges between 15 and 17 days of age.

The T-D group responded to the anticholinergic effects of scopolamine at 15 days of age, 1-2 days earlier than controls, indicating advanced cholinergic inhibitory functioning as a result of the early hyperthyroidism. The results of the present study, therefore, suggest that neonatal hyperthyroidism yields both enhancement of arousal during development, although accelerated locomotor capacities cannot be discounted (Davenport \& Gonzalez, 1973; Murphy \& Nagy, in press), and accelerated maturation of compensatory inhibitory capacities.

\section{REFERENCES}

Agrawal, H. C., \& Himwich, W. A. Amino acids, proteins and monoamines of developing brain. In W. A. Himwich (Ed.), Developniental neurobiology. Springfield: Charles C Thomas. 1970. Pp. 287-310.

Campbell, B. A.. Lytle, L. D., \& Fibiger, H. C. Ontogeny of adrenergic arousal and cholinergic inhibitory mechanisms in the rat. Science, 1969, 166, 637-638.

Carlton, P. L. Cholinergic mechanisms in the control of behavior by the brain. Psychological Revien: 1963, 70, 19-39.

Davenport, J. W., \& Gonzalez, L. M. Neonatal thyroxine stimulation in rats: Accelerated behavioral maturation and subsequent learning deficit. Journal of Comparative and Physiological Psychology, 1973, 85, 397-408.

Davenuurt, J. W., Hagquist, W. W., \& Hennies, R. S. Neonatal hyperthyroidism: Maturational acceleration and learning deficit in triiodothyronine-stimulated rats. Physiological Psychology, 1975, 3, 231-236.

Emlen. W. Segal, D. S., \& Mandell, A. J. Thyroid state: Effects on pre- and postsynaptic central nonadrenergic mechanisms. Science, 1972, 175, 79-82.

Engstrom, G., Strombom, U., Svensson, T. H., \& Waldeck, B. Brain monoamine synthesis and receptor sensitivity after single or repeated administration of thyroxine. Journal of Neural Transmission, 1975, 37, 1-10.

Engstrom, G., Suensson, T. H., \& Waldeck, B. Thyroxine and brain catecholamines: Increased transmitter synthesis and increased receptor sensitivity. Brain Research, 1974, 77, 471-483.

GeEL, S. E. \& \& Timiras, P. S. Influence of hyperthyroid is $m$ and of thyroxine on the acetylcholinesterase and cholinesterase activities in the developing central nervous system of the rat. Endocrinology, 1967, 80, 1069-1074.

Hamburgh, M., \& Flexner, L. B. Biochemical and physiological differentiation during morphogenesis -- XXI Effect oî hypothyroidism and hormone therapy on enzyme activities of the developing cerebral cortex of the rat. Journal of Neurochemistry, 1957. 1. 279-288.

Murphy, J. M.. \& NAGY, Z. M. Neonatal thyroxine stimulation accelerates the maturation of both locomotor and memory processes in mice. Journal of Comparative and Physiological Psychology, in press.

NaGY, Z. M., Murphy, J. M.. \& Ray, D. Development of behavioral arousal and inhibition in the Swiss-Webster mouse. Bulletin of the Psychonomic Society. 1975, 6. 146-148.

OAKLey, D. A.. \& Plotkin, H. C. Ontogeny of spontaneous locomotor activity in the rabbit, rat, and guinea pig. Journal of Comparative and Physiological Psychology, 1975, 89, 267-273.

Peterson, N. A., Nataf, B. M., Chaikoff, I. L., \& RAGUPATHY, E. Uptake of injected ${ }^{13}{ }^{3}$ I-labeled thyroxine. triiodothyronine and iodide by rat brain during various stages of development. Journal of Neurochemistry, 1966, 13, 933-943.

RAY. D. The role of emerging cholinergic mechanisms in the ontogeny of response inhibition in the developing mouse. Unpublished doctoral dissertation. Bowling Green State University, 1975.

Schapiro. S. Some physiological. biochemical, and behavioral consequences of neonatal hormone administration: Cortisol and thyroxine. General and Comparative Endocrinology. 1968, 10. $214-228$.

(Received for publication April 23, 1976.) 